\title{
Computational and Experimental Investigation of Runner for Gravitational Water Vortex Power Plant
}

\author{
R. Dhakal, T.R Bajracharya, S.R Shakya, B. Kumal \\ Faculty of Engineering \\ Tribhuvan University Institute of Engineering \\ Thapathlai Campus, Central Campus \& Kantipur \\ Engineering College \\ Kathmandu, Nepal \\ rbndhakal@gmail.com \\ K. Khanal \\ Department of Mechanical Engineering \\ School of Engineering, Kathmandu University \\ Kavre, Nepal
}

\author{
S. J. Williamson \\ Faculty of Engineering \\ University of Bristol \\ Bristol, UK \\ Sam.Williamson@bristol.ac.uk \\ S.C. Itani, D.P. Ghale \\ Faculty of Engineering \\ Acme Engineering College, Purbanchcal University \\ National College of IT, Pokhara University \\ Kathmandu, Nepal
}

\begin{abstract}
The gravitational water vortex power plant (GWVPP) is a new type of low head turbine system in which a channel and basin structure is used to form a vortex, where the rotational energy from the water can be extracted through a runner. This study is focused on the optimization of the runner to improve the efficiency of the GWVPP. Computational fluid dynamics (CFD) analysis is carried out on three different runner designs with straight, twisted and curved blade profiles. ANSYS CFX was used to analyze the fluid flow through the channel, basin, turbine hub and blade, and results were used to evaluate the efficiency of each of the runner designs. The CFD analysis showed curved blade profile to be the most efficient profile, with a peak efficiency of $82 \%$, compared to $46 \%$ for the straight blade runner and $63 \%$ for the twisted blade version. An experimental test of the turbine system was carried out to validate the runner analysis, in a scale version of the GWVPP. The testing showed that the runner behaved as predicted from the CFD analysis, and had a peak efficiency point of $71 \%$ at $0.5 \mathrm{~m}$ head.
\end{abstract}

Keywords: Low head turbine, vortex, computational fluid dynamics, experimental turbine testing, blade profile

\section{INTRODUCTION}

There are 1.2 billion people around the world that lack access to electricity, some $85 \%$ of them in rural areas [1] [2]. Based on current trends, 1.2 billion people or $15 \%$ of the world's population will still lack access in 2030 [3].The economic growth and improvement in people's living standards depends on the utilization of electrical energy, especially for rural communities. For the economic advancement of the society, the United Nations has targeted universal electrical access by 2030. For this ambitious target, investment of $\$ 36$ billion per year in 2010-2030 is needed [3]. This growing demand for electrical energy, whilst reducing carbon emissions, is one of the main reasons pushing the advancement and implementation of renewable resources such as solar photovoltaics, wind and hydropower. Implementing these in rural areas allow communities to generate and manage their own resources locally.

Micro hydropower plants are small scale hydropower plants ranging from $5 \mathrm{~kW}$ to $100 \mathrm{~kW}$ [4], with pico hydropower considered to be below $5 \mathrm{~kW}$ generation [5]. This system can be easily designed and developed for electricity load ranging from single home to small building and industry [28].Generally, micro hydropower systems do not need large dams or reservoirs, with water from a river is partially diverted through an intake canal to a forebay tank, and then fed via penstock to a lower elevation. The water turbine, normally sheltered in a power house, transforms the energy in the water flow into electrical energy, with power generation efficiencies able to reach up to $90 \%$ [6]. There are two main types of turbine, impulse and reaction, each suitable for different types of environmental conditions. Impulse turbines are more suitable for higher heads, in the micro hydropower domain above 20 meters, whilst reaction turbines are more suitable to lower heads, under 10 meter. Figure 1 shows micro hydro turbine classifications.

There are thought to be tens of thousands of pico and micro hydropower plants in China and significant numbers in Nepal, Sri Lanka, Pakistan, Vietnam and South-East Asia, and Peru. There are also hundreds of low head micro hydropower plants in Europe and many part of North America. The estimate for micro hydropower capacity in China was about $500 \mathrm{MW}$ at the end of 2008 [8]. Micro hydro is in most cases "run-of-river", with no dam or water storage, and is one of the most cost-effective and environmentally benign energy technologies to be considered for rural electrification. For economic viability of rural electrification, expansion of productive use of electricity is essential [26]. Studies in Nepal 
have shown that rural electrification alone has had minimal negative impact on agricultural or industrial production but has provided a cost-effective way to provide mechanical enduses to improve the lives of rural communities [7]. The life cycle assessment of micro hydro in rural Thailand for twenty years concluded that smaller hydro power systems have a greater environmental impact per kilowatt hour, and perform less well environmentally than larger hydropower systems. However, the micro hydropower system yields better environmental and financial outcomes than diesel generator or grid connection alternatives [9].

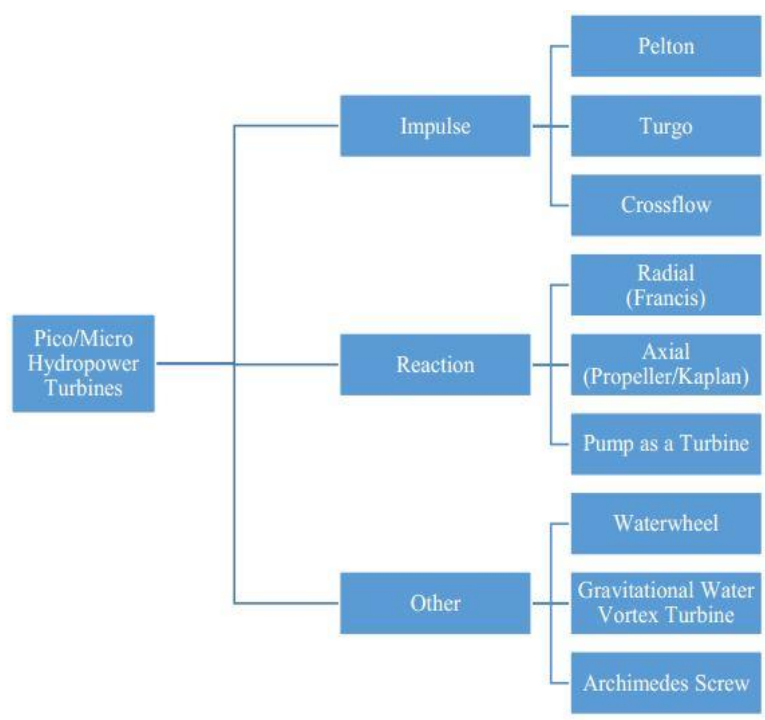

Fig.1: Micro hydro turbine classification

Austrian engineer Franz Zotlöterer has recently developed a method of initiating and extracting energy from water vortices for micro hydropower generation, known as the Gravitational Water Vortex Power Plant (GWVPP) [10]. More than 50 GWVPPs have already been installed in Europe since 2007 with more are under construction. However, there are currently few installations in other parts of the world [10] [11] [12].Compared to other hydroelectric generation technologies, the GWVPP have greatest potential at low-head sites and, unlike conventional reaction or impulse turbines, they have the potential for maintaining high efficiencies even as the head approaches nearly zero. This is because the head is just needed to create an artificial vortex and no other significance of higher head for this turbine system [13].

GWVPPs consist of a canal, a basin structure and turbine. Water through the canal is tangentially fed into the round basin structure to form powerful water vortex. The kinetic energy of the water vortex is converted to electric energy through the turbine runner situated in the center of water vortex. An exit hole is made at the bottom of the basin thorough which the water vortex discharges [14]. Unlike most low-head micro hydropower plants, this turbine does not works on the pressure differential across the turbine runner blades to create the torque on the output shaft, instead it operates through the dynamic force of the vortex. The turbine system gives a useful output power as well as aerating the water. Thus this turbine is a milestone in hydrodynamic development, as previously energy was required to aerate water but now this technology uses water aeration process to extract electrical energy.

Unlike most micro hydropower technologies, fish and small debris can pass through an operating GWVPP without causing damage to the turbine or harm to the fish. The GWVPP has several further claimed advantages, such as homogenously disseminating contaminants in the water, increasing the heat of evaporation so water can reduce the temperature itself at rising temperatures in summer and also through the creation of vortex dissolved oxygen concentration can be improved [10].

There have been a number of research studies on the GWVPP, focusing on the optimization of the basin structure design for the formation of the water vortex. Wanchat et al [15] [16] indicates the important parameters which can determine the water free vortex kinetic energy and vortex configuration are height of water in the canal, the orifice diameter, the condition of inlet and basin configuration. They propose a cylindrical tank with the incoming flow guided by a plate as a suitable configuration to create the kinetic energy water vortex and an orifice at the bottom center as the optimum design. Mulligan et al [14] discuss the ratio between the basin diameter and outlet tube diameter, concluding that to maximize the power output in cylindrical basin, the ratio of outlet tube diameter to basin diameter lies within 14\%-18\%. The research conducted at Tribhuvan University, Nepal [17] [18] concludes the vortex formation is aided by the use of conical basin structure, with the output power and efficiency improved compared to a cylindrical basin structure with the optimum position of runner. Moreover, the research also concludes that the for a given head and flow the different geometrical parameters that governs the design conical basin design of a GWVPP are the basin opening, the basin diameter, the notch length, the canal height and the cone angle [19], which are shown in Fig. 2.

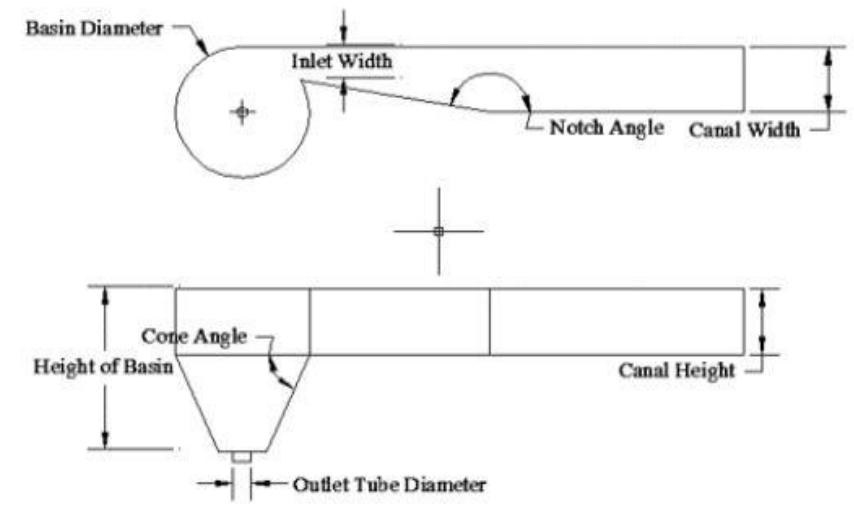

Fig.2: Various geometrical parameter of basin structure taken for the study in the previous research

A team from Trinity College, Dublin [20] investigate the operating conditions of the GWVPP. The inlet flow rates, inlet water height, runner blade sizes and blade numbers were all varied experimentally, recording the turbine rotational speed, vortex height and output torque for each setting using Prony brake dynamometer. It was found that the turbine efficiency increases with blade area and blade number for the blade configurations tested. Finally, of three inlet heights 
(height of water in the basin) tested, a height of $25 \mathrm{~cm}$ above the tank base (35\% of the overall tank height) was found to be optimum for turbine performance. A maximum measured efficiency of $15.1 \%$ was found in these tests, however the system was not optimized for this operation.

Current research has solely focused on the different parameters that govern the design of the basin structure or conducting experimental studies on the turbine system. However, no research has been published on the design and optimization of the turbine runner. Therefore, this paper describes a numerical and experimental study that has been conducted on gravitational water vortex energy system to select a suitable runner design, assessing the design using ANSYS CFX and validating the selected runner design by an experimental study.

\section{THEORETICAL DESIGN OF RUNNER}

In a water vortex, water swirls around an empty core, known as a vortex center, of decreasing radius as the vortex height above the outlet plain reduces. In classical hydrodynamics, a free, irrotational vortex can be defined as a flow pattern with streamlines in concentric circles. In reality, since all fluids have viscosity, no flow is truly irrotational. However, flows can be successfully studied by assuming them to be inviscid and irrotational because of the negligible viscous effects [21]. In a free vortex, fluid particles do not rotate as they translate in circular paths around the vortex center. For an irrotational vortex, the radial velocity $v_{r}$ of a water particle is zero, while the tangential velocity $v_{0}$ is given by:

$$
v_{\theta}=\frac{\Gamma}{2 \pi r}
$$

Where $\Gamma$ the circulation and $r$ is is the radius of the water particle. Fig. 3 shows is the general formulation of inlet and outlet velocity triangles for an impulse type turbine runner. In Fig. 3, $u$ denotes the tangential velocity of runner, $v$ is the absolute velocity of the jet, $R$ is the relative velocity of the jet with respect to the runner, $v_{w}$ is the whirl velocity, and subscript 1 is at the inlet to the runner and 2 is at the exit of the runner. It is normally assumed that $R_{1}=R_{2}$, with any losses in the runner blade assumed to be negligible.

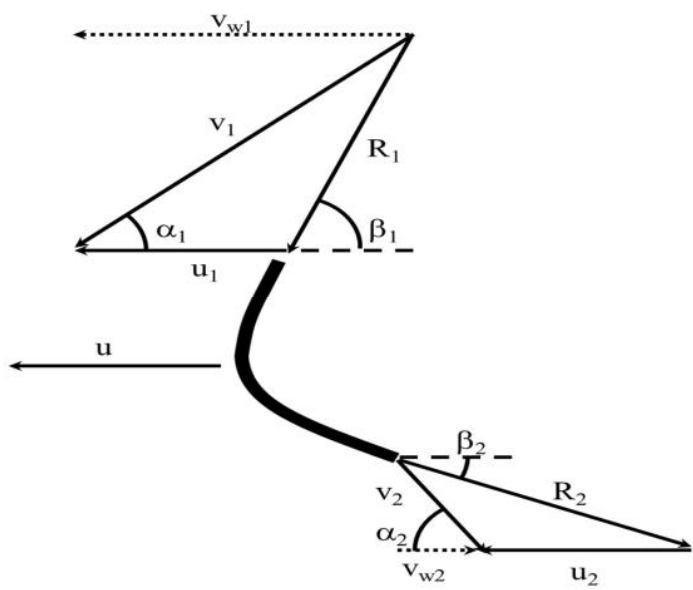

Fig.3: Inlet and outlet velocity triangles for a typical impulse turbine runner.

In this type of impulse turbine, high velocity fluid strikes the runner deflecting the fluid stream, causing a change in momentum on the fluid and exerting a reacting force on the turbine runner. The GWVPP runner blade design was also carried out using the same method. However, the water flowing into a Pelton Wheel assumes that the flow only moves in one direction. Conversely, in the GWVPP the water will be moving in two dimensions, horizontally and vertically. In order to simplify analysis, it is possible to assume that the most of the energy of a water vortex can be harnessed horizontally and it is negligible on vertical side. In an impulse turbine, the inlet jet velocity is constant, however for the GWVPP the inlet velocity varies across the radius of the vortex, as described by (1). Therefore, the velocity triangles shown in Fig. 3 vary across the radius of the runner.

The maximum power output for the blade can be obtained with the following equation

$$
P_{\text {shaft }}=\rho Q U\left(U-V_{1}\right)(1-\cos \beta)
$$

where $P_{\text {shaft }}$ is the shaft output power, $r$ is the water density, $Q$ is the water flow rate, $U$ is the tangential velocity, $V_{l}$ is the absolute inlet velocity, $\beta$ is the deflected angle for the water flow. Again, as the velocities will vary across the runner radius, the output power will need to be integrated to calculate it accurately.

The flow of water in the turbine impinges on the blade of turbine as shown in Fig. 4. If the velocity of water is more than that of turbine the water causes the runner to accelerate. Then the water turbine would rotate and there is relative motion between liquid and blade that gives useful power [22].

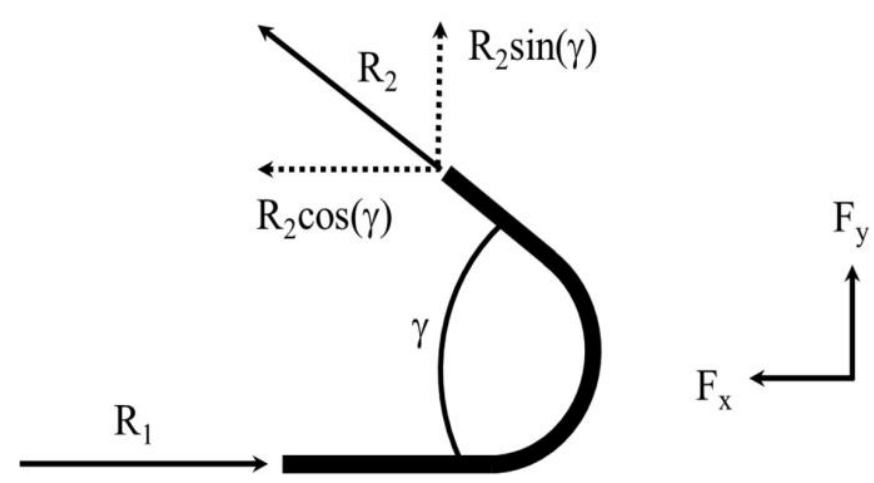

Fig.4: Forces acting on the runner blade from the impact of the water.

The force of the water on the runner blade is given by the following equations:

$$
F=\sqrt{\left(F_{x}^{2}+\left(F_{y}^{2}\right)\right.}
$$




$$
\begin{gathered}
F_{x}=\rho Q_{r} R_{2}(\cos \gamma+1) \\
F_{y}=\rho Q_{r} R_{2} \sin \gamma \\
R_{1}=V_{\theta}-u
\end{gathered}
$$

where $F$ is the total force on the turbine blade, $F_{x}$ and $F_{y}$ are the reaction force due to the water on the turbine blade in the $\mathrm{x}$ and $\mathrm{y}$ axis directions respectively, and $\gamma$ is the included angle of the turbine runner blade. Torque and efficiency of the turbine can be calculated from the following equations:

$$
\begin{gathered}
T=\frac{60 P_{\text {shaff }}}{2 \pi n} \\
P_{\text {hyd }}=\rho Q g H \\
\eta=\frac{P_{\text {shaff }}}{P_{\text {hydi }}}
\end{gathered}
$$

where $T$ is the output torque of the turbine, $n$ is the rotational speed of the output shaft in rpm, $P_{\text {hyd }}$ is the hydraulic input power, $g$ is acceleration due to gravity, $H$ is head of water, and $\eta$ is the turbine efficiency.

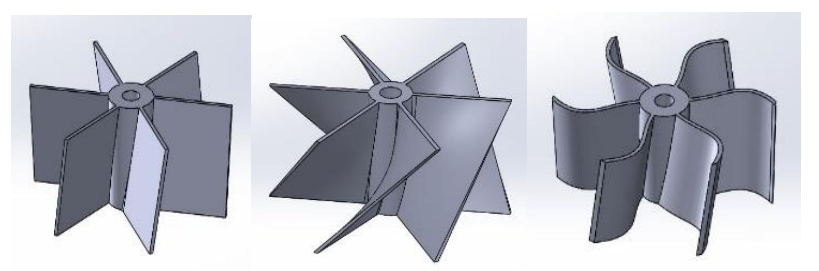

Fig.5: 3D CAD model of three different runners With straight, twisted and curved blade profiles.

\section{ANALYSIS OF RUNNER DESIGNS}

Computational fluid dynamics (CFD) deduce the complex governing equations of a fluid system into a set of simpler algebraic equations which are easier to solve [23]. A CFD process includes three steps: pre-processing, which specifies boundary conditions, solver, which defines convergence criteria and post processing, which analyzes the results. The water vortex was considered based on the assumption of steady, axisymmetric and incompressible flow. The continuity equation and the Navier- Stokes equations in cylindrical coordinates are described by the following equations:

$$
\begin{gathered}
\frac{\partial V_{r}}{\partial r}+\frac{\partial V_{z}}{\partial z}+\frac{V_{r}}{r}=0 \\
V_{r} \frac{\partial V_{Q}}{\partial r}+V_{z} \frac{\partial V_{Q}}{\partial z}-\frac{V_{r} V_{Q}}{r}=v\left(\frac{\partial^{2} V_{Q}}{\partial r^{2}}+\frac{\partial V_{Q}}{r \partial r}-\frac{V_{Q}}{r^{2}}+\frac{\partial^{2} V_{Q}}{\partial z^{2}}\right)
\end{gathered}
$$

$$
\begin{aligned}
& V_{r} \frac{\partial V_{F}}{\partial r}+V_{z} \frac{\partial V_{r}}{\partial z}-\frac{V_{T}^{2}}{r}+\frac{\partial \rho}{\rho \partial z}=v\left(\frac{\partial^{2} V_{F}}{\partial r^{2}}+\frac{\partial V_{r}}{r \partial r}-\frac{V_{r}}{r^{2}}+\frac{\partial^{2} V_{r}}{\partial z^{2}}\right)(12 \\
& V_{r} \frac{\partial V_{z}}{\partial r}+V_{z} \frac{\partial V_{z}}{\partial z}-\frac{\partial \rho}{\rho \partial z}=g+v\left(\frac{\partial^{2} V_{z}}{\partial r^{2}}+\frac{\partial V_{z}}{r \partial r}+\frac{\partial^{2} V_{r}}{\partial z^{2}}\right)
\end{aligned}
$$

Where, $V_{\theta}, V_{r}$ and $V_{z}$ are tangential, radial and axial velocity components respectively, and $v$ is kinematic viscosity [24]. Due to the complexity of the equations, it is impossible to get an analytical solution directly, therefore CFD methods are used to approximate a solution to these equations.

Two fluid domains were created in SolidWorks: a stationary domain which the fluid flows in, and a rotating domain which the turbine model rotates in. These domains were imported in ANSYS CFX and then discretized to generate smaller units by hex dominant meshing with free face mesh type set to "All Quadrilaterals" to produce uniform meshing. Similar domain creation and meshing process were used for all three runner models.

Hence we can have a clear picture of the parameters that affect the design of the runner. The blade inlet angle should match the relative velocity inlet angle to reduce losses, which changes across the width of the runner. As the basin is conical, the tangential water velocity also changes across the height of the runner, therefore the angle needs to be adjusted across the height of runner. The blade angle $\gamma$ has effects the magnitude of horizontal and vertical component of forces acting on the blade. Three models with six blades and different blade profiles were designed namely straight, twisted and twisted and curved blade profile over which CFD analysis is performed, shown in Fig. 5.

The inlet boundary conditions for the stationary domain were specified with an inlet velocity of $0.3 \mathrm{~m} / \mathrm{sec}$ and outlet condition was characterized for static pressure of 1 atm. As multiple domains were used, water and air, fluid values of water $=1$ and air at $25^{\circ} \mathrm{C}=0$ was set at the inlet of stationary domain and vice versa at opening of the rotating domain. The domain motion for rotating domain was changed to rotating type with angular velocity ranging from 50 to $250 \mathrm{rpm}$ in anticlockwise direction. The water flow is considered as incompressible, therefore the turbulence model k-Epsilon had been used for validation process. The maximum iteration number was set to 300 with RMS residual type and residual type and residual target of $1.0 \mathrm{e}-4$. The boundary conditions for the rotating and stationary domains are shown in Fig. 6.

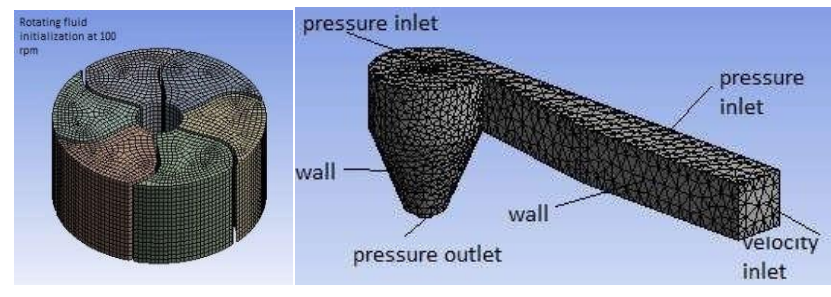

Fig. 6: Meshing and boundary condition for rotating and stationery domain. 
The stream line flow and velocity distribution shows that the velocity of the vortex pool which strikes the runner is approximated $1.3 \mathrm{~m} / \mathrm{sec}$ at radii from $60 \mathrm{~mm}$ to $120 \mathrm{~mm}$, Fig. 7 . This value of velocity, which has significance for the production of torque on the shaft through the blade, is taken for the analysis of the runner in the rotating domain. The streamlines also predict that it is likely that the area of the stream of water which strikes the blade will be maximum for the blade with curved profile.

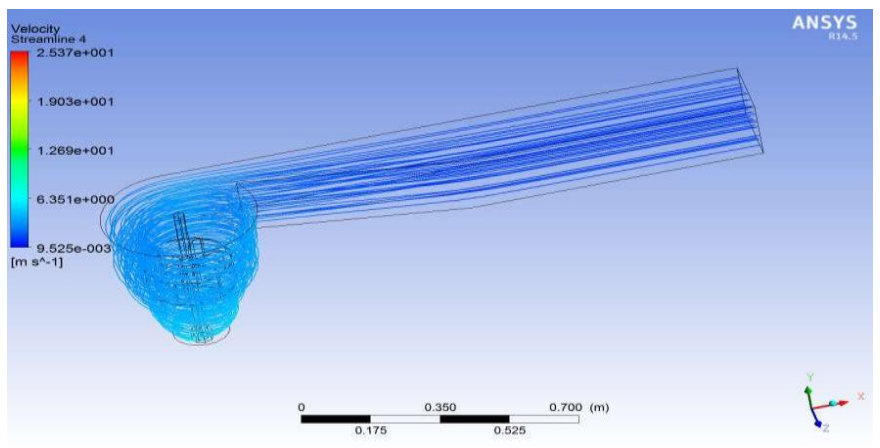

Fig.7: Streamline flow in the stationary domain, with runner in the optimum position

For each of the turbine models, the resultant torque is the summation of torque produced by each blades mounted on the hub and hub itself taken in the direction along the axis of rotation. From this, power output and efficiency was calculated, using equations (7) and (9). The result obtained showed that the curved profiled turbine with efficiency $82.4 \%$ as the best one in comparison with straight blade and twisted, as shown in Fig. 8, with the efficiency of straight blade turbine and twisted blade turbine were $46.3 \%$ and $63.5 \%$ respectively. When the rotational speed of the turbine changes between 50 to $200 \mathrm{rpm}$, the curved profile still remains the most efficient runner design.

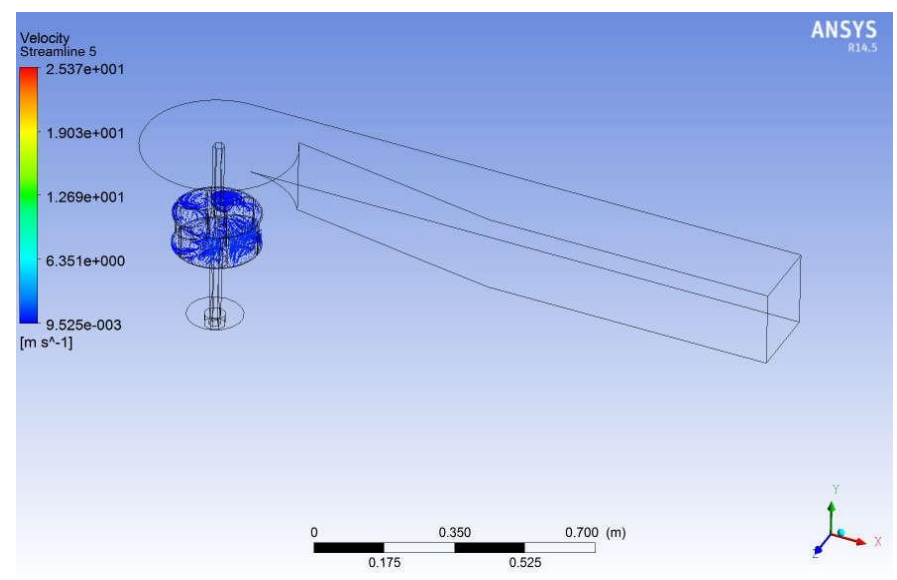

Fig. 8: Streamline flow in the rotational domain, with runner in the optimum position or each of the turbine models

The results matches the theoretical concepts of impacts of free jets on different profiled blades as the curved profile blade is best due to the presence of larger surface area to impinge the flow. Moreover the curved profile blade has less losses form the streamflow as it is matching the velocity angle of the vortex better than the straight and twisted one. Using the calculated torque and efficiency obtained from the

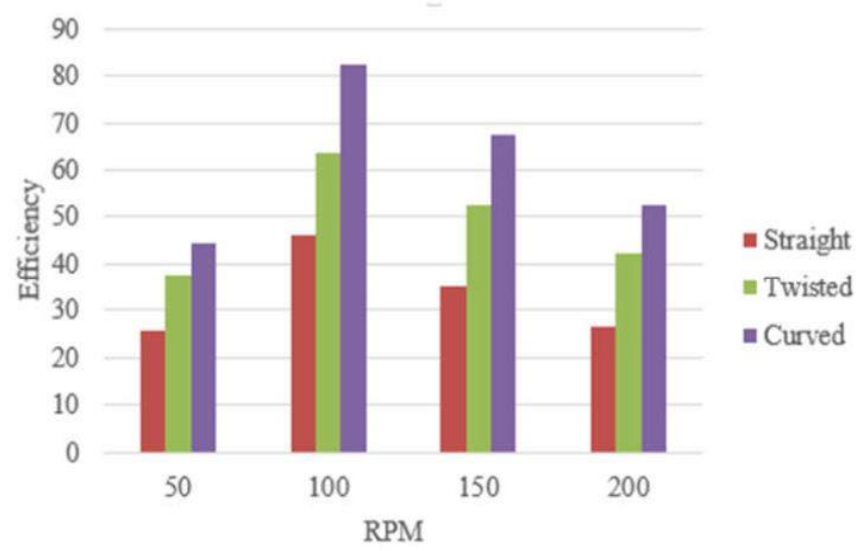

simulation process, the curved blade profile was selected as best blade profile for the GWVPP, which is taken forward into the experimental validation phase.

Fig.9: Calculated efficiency of the 3 turbine runner designs across a speed range.

\section{A. Optimization of Blade Angle on Curved Profile Runner Design}

Further CFD analysis was conducted to determine the optimum angle of the blade on the hub for the curved blade profile. The blade angle was varied between $15^{\circ}$ and $25^{\circ}$ at $1^{\circ}$ intervals, with the efficiency calculated at each point. The results of this analysis is presented in Fig. 9. The maximum efficiency was found to be at a blade angle of $19^{\circ}$, with an efficiency of over $80 \%$, with only a small decrease in efficiency with blade angles between $18-22^{\circ}$. At the optimum angle, the blade is able to direct the stream of water to strike blade perpendicularly so that it can produce the maximum thrust.

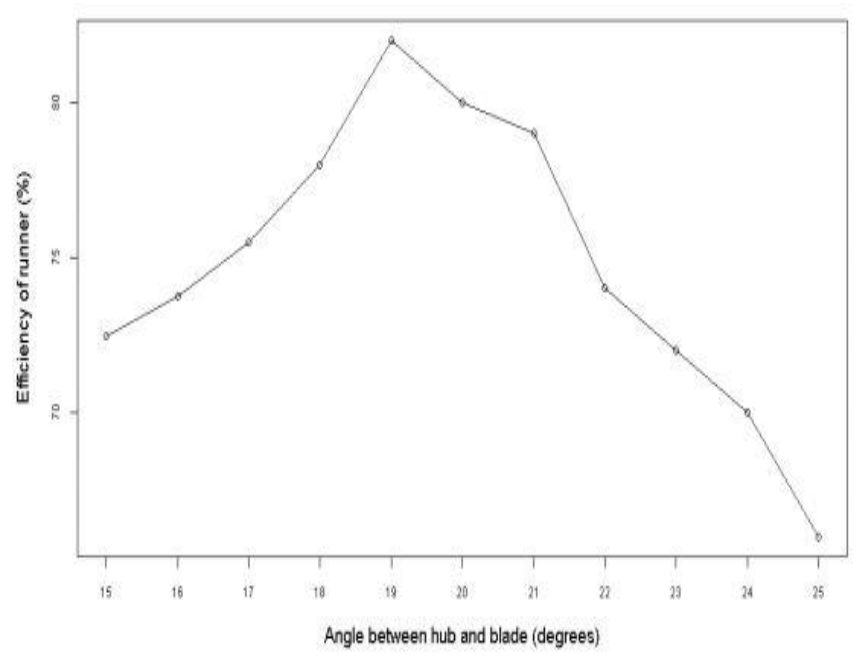

Fig.10: Calculated efficiency vs angle between hub and blade for the curved blade profile simulated in CFD. 


\section{EXPERIMENTAL TESTING OF GWVPP}

A reduced scale model of the GWVPP was constructed, following the rules for geometric, kinetic and dynamic similarity. The curved profile runner model has a diameter of $300 \mathrm{~mm}$, runner height of $100 \mathrm{~mm}$ and runner hub of diameter $40 \mathrm{~mm}$. The laboratory setup is shown in Fig. 10. This has a basin diameter of $400 \mathrm{~mm}$, the canal height is $200 \mathrm{~mm}$, with a notch angle of 10 degree and a cone angle of approximately $23^{\circ}$. The system has a total head of $1 \mathrm{~m}$ and operates with the flow rate of $0.004 \mathrm{~m} 3 / \mathrm{s}$, which is provided by a pump recirculating the water flow. The canal is $880 \mathrm{~mm}$ long and $200 \mathrm{~mm}$ wide. A photo of the fabricated experimental setup is shown in Fig. 11, with the runner shown in Fig. 12. The canal is $880 \mathrm{~mm}$ long and $200 \mathrm{~mm}$ wide. A photo of the fabricated experimental setup is shown in Fig. 11, with the runner shown in Fig. 12.

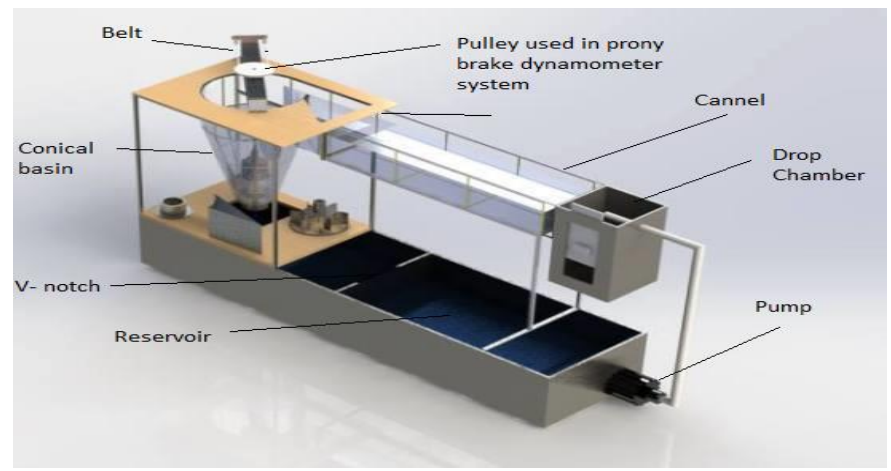

Fig. 11: Schematic of scaled experimental setup.

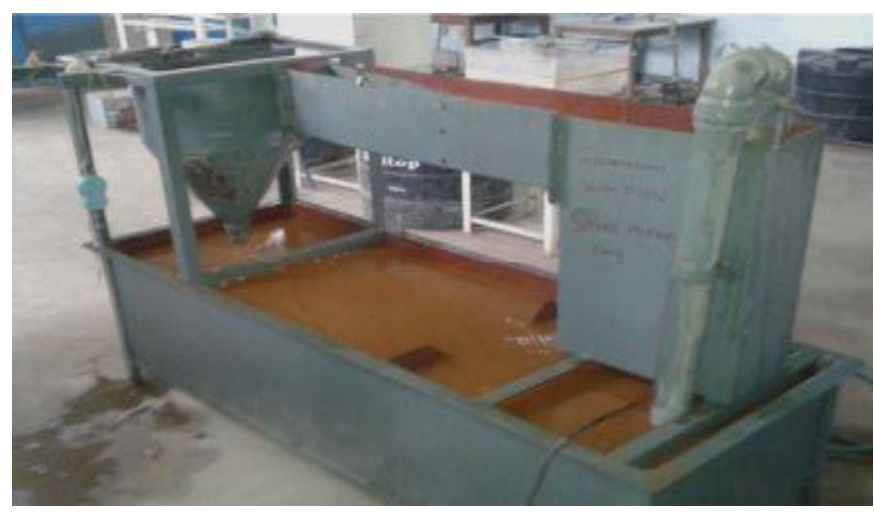

Fig.12: Fabricated experimental setup

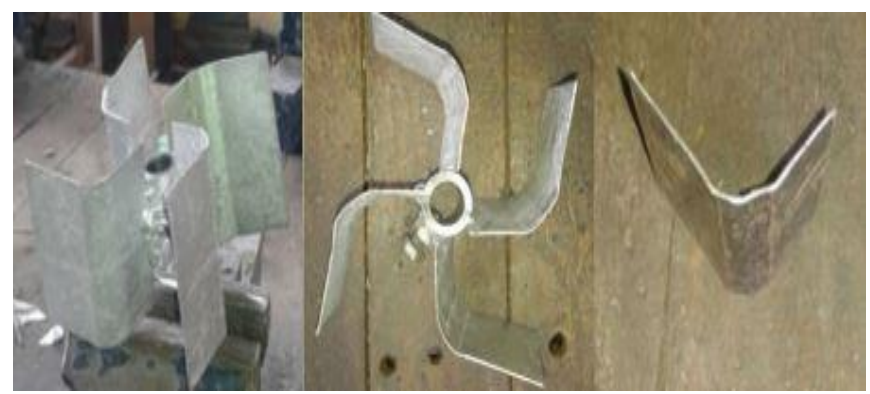

The inlet velocity was measured by using the float method, where an object was dropped into the canal and the time taken by the float to cover a distance of $0.5 \mathrm{~m}$ was measured. This was repeated five times to calculate the average velocity rate A correction factor of 0.85 was applied to the measured velocity as walls of the canal are smooth [25], with the mean inlet velocity calculated to be $0.03 \mathrm{~m} / \mathrm{s}$.

In previous work, the maximum output power was found at a runner position of $65-75 \%$ of total height of basin from top position [19]. Therefore, the runner position for these tests was $400 \mathrm{~mm}$ from the bottom of the basin. A Prony brake dynamometer is used for the measurement of torque, which consists of a pulley of $110 \mathrm{~mm}$ diameter fitted to the output shaft and rope of $7 \mathrm{~mm}$ diameter is connected to two digital weight balance through the pulley, as shown in Fig. 13. One weight balance is suspended through a small pulley carrying weight and another is fixed at top of the basin. The load at the weight balance is increased gradually to apply the load on the output shaft and corresponding value of speed is noted.

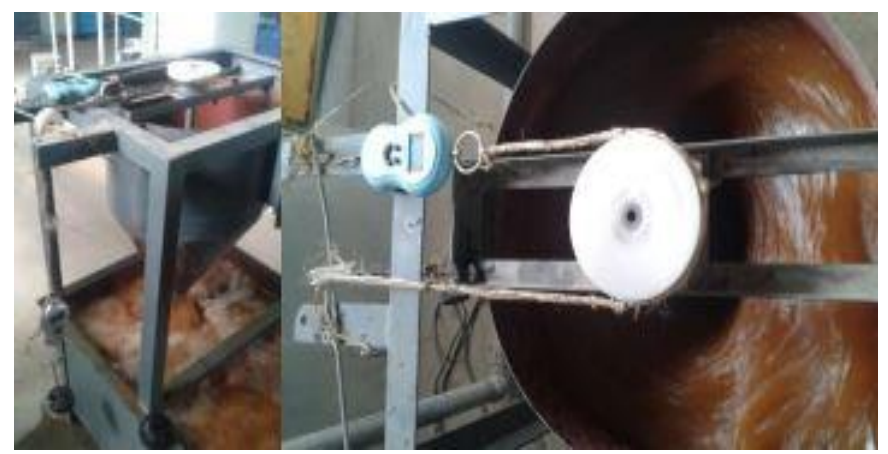

Fig.14: Prony brake dynamometer system.

The output power from the turbine can then be calculated using the following equation:

$P_{\text {shaft }}=\frac{2 \pi g v_{\text {pulley }}{ }^{n}}{60}\left(M_{\text {weight }}-M_{\text {cowntenweight }}\right)$

Where $r_{\text {pulley }}$ is the pulley radius, $M_{\text {weight }}$ is the mass on one side of prony brake dynamometer and $M_{\text {counterweight }}$ is the mass on the other side of Prony brake dynamometer.

\section{EXPERIMENTAL RESULT AND DISCUSSION}

Figure 15 shows the measured efficiency of the GWVPP across a range of speeds. The results show that the maximum efficiency of $71 \%$ can be achieved in the range between 120 and $140 \mathrm{rpm}$ using the optimized curved blade runner. When compared with previous research [15] [20], the efficiency of the conical basin system is much larger as the vortex strength is aided to about 1.6 times and also the runner position also effect the output power [19]. The use of conical basin structure with optimum position of runner and optimizing the blade 
angle and profile is the main reason behind the maximization of the output power. Comparing the simulation and experimental results, the calculated efficiency in the CFD compares well to the measured experimental efficiency with a $10 \%$ difference. The difference can be attributed to increased losses in the experimental testing, through leakage, increased surface friction due to manufacturing techniques, and mechanical losses that are not accounted for the in the CFD model.

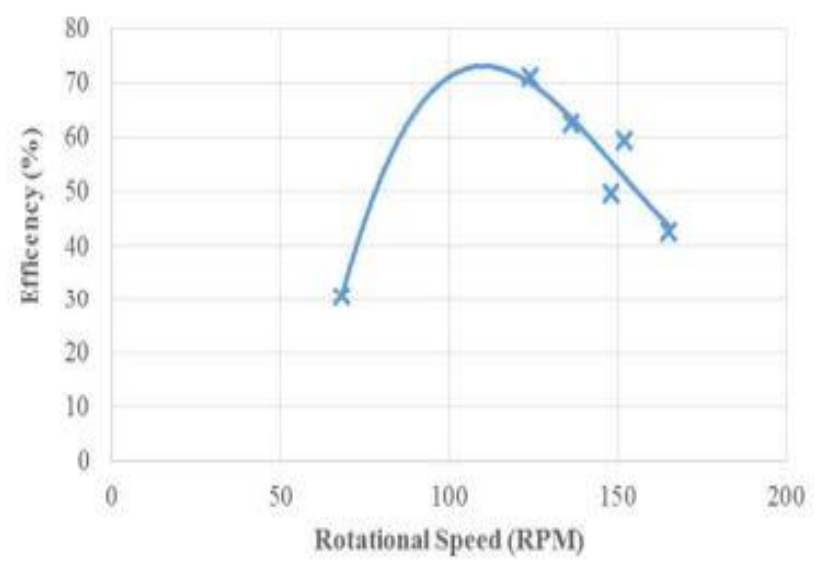

Fig. 15: Efficiency vs Rotational Speed

As can be seen in Fig. 15, the efficiency is dependent on the speed of rotation. Therefore, when coupled with an electrical load, this load will have to be maintained at a constant value to ensure that no non-linear effects occur, causing a collapse of the turbine speed and output. This can be achieved by the use of a suitable electronic load controller (ELC) [5]. Moreover, these plants have a common problem of very low utilization of electricity generation during off peaks hours resulting in the low plant factor. Using a Micro-Grid (also called local grid), the issue of loss of plant efficiency as a result of under-utilization of electricity generation during off peak hours can also be addressed [26]. The speed of rotation for this turbine is very slow at its maximum efficiency point, therefore matching it to a standard generator to produce 50 or $60 \mathrm{~Hz}$ output frequency will require a step-up in speed through either a gearbox or belt drive system.

The output of the experimental setup was $14 \mathrm{~W}$, which would not provide a useful amount of power for an off-grid household or community. However, using hydrodynamic scaling laws [27], this system can be designed to meet any changed in environmental conditions for head or flow rate. For example, a pilot system has been designed to produce $1.6 \mathrm{~kW}$ for an off-grid community in Nepal. The available head at site is $1.5 \mathrm{~m}$, and flow rate is $0.2 \mathrm{~m}^{3} / \mathrm{s}$. For this design, a basin diameter of $2000 \mathrm{~mm}$ was chosen with a canal width of 1000 $\mathrm{mm}$, and the predicted maximum operating efficiency speed is $95 \mathrm{rpm}$. The construction of a GWVPP does not require any specialist tools or equipment, the workshop will only require to bend and weld sheet metal. Therefore, this turbine is ideal for developing countries with more basic workshop facilities available.
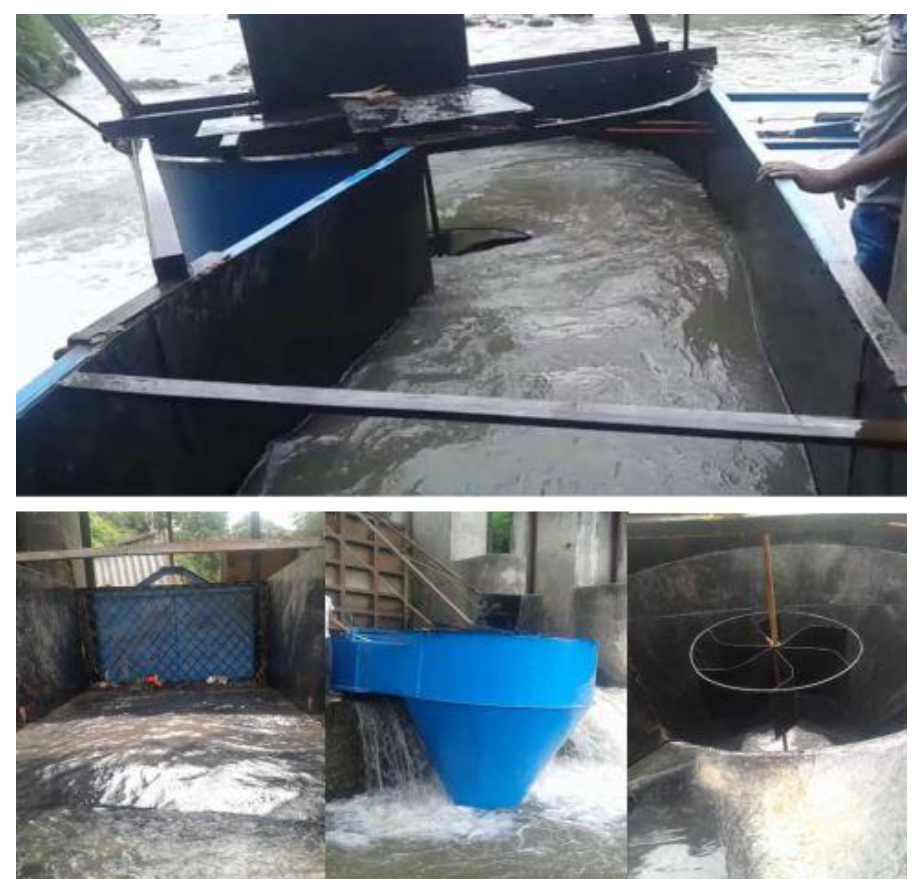

Fig. 16: Pilot Project using conical basin structure (canal, gate, basin structure and runner)

\section{CONCLUSION}

The gravitational water vortex power plant is an emerging technology in context of low head hydropower, providing a suitable option for rural electrification. A method for designing the runner for the GWVPP has been proposed using basic hydrodynamic equations, and three alternative runner designs were proposed. CFD analysis for three different runner blade profiles showed that a curved blade profile is most suitable for the GWVPP, with an angle between the blade and the hub of $19^{\circ}$, achieving a calculated maximum efficiency of over $80 \%$. An experimental test rig was constructed to validate the CFD analysis, and achieved a measured efficiency of $70.9 \%$. The difference between experimental testing and CFD analysis was acceptable, and was mainly attributed to leakage and mechanical losses, nonideal construction of the canal and basin with increased surface friction, and increased rotational speed of the turbine. The GVWPP can be scaled using hydrodynamic similarity, and therefore offers an opportunity for power generation in the remote villages where it is difficult to provide the national power grid. Its simple design also allows it to be fabricated in basic workshops, allowing the design to be replicated across the world.

\section{ACKNOWLEDGMENT}

This study acknowledges the financial support from Tribhuvan University, Kantipur Engineering College, Dhapakhel, Lalitpur, Nepal. The authors would like to thank the Himalaya College of Engineering, Chyasal, Lalitpur, 
Nepal for providing test rig for the experimental reading, and are obliged to Center of Energy Studies, Central Campus, Pulchowk, Electrical Energy Management Group, University of Bristol and Department of Automobile and Mechanical Engineering for their technical support. The authors would like to thank all the member of Vortex Energy Solution Pvt. Ltd for funding the pilot project and 3R Concern for fabrication of runner models and $1 \mathrm{kw}$ pilot project. Also like to thank to Acme Engineering College and Kantipur City College for their help in doing computational study.

\section{REFERENCES}

[1] International Energy Agency, "World Energy Outlook," Internation Energy Agency, Paris, 2015.

[2] K. Kaygusuz, "Energy for sustainable development: A case of developing countries," Renewable and Sustainable Energy Reviews, vol. 16, no. 2, pp. 11161126, 2012.

[3] R. H. Jones, Energy Poverty: How to make modern energy access universal?, Paris: International Energy Agency, 2010.

[4] Alternative Energy Promotion Centre, Renewable Energy Data Book, Khumaltar, Lalitpur: Alternative Energy Promotion Centre, Governemnt of Nepal, 2011.

[5] N. P. A. Smith, "Induction generators for stand-alone micro-hydro systems," in Proc. IEEE Int. Conf. on Power Electronics, Drives and Energy systems for industrial growth, New Delhi, 1996.

[6] J. Twidell and T. Weir, Renewable Energy Resources, New York: Taylor and Francis, 2006.

[7] O. Paish, "Small hydro power: technology and current status," Renewable and Sustainable Energy Reviews, vol. 2002, no. 6, pp. 537-556, 2002.

[8] V. Nelson, Introuduction to Renewable Energy, Boca Raton: CRC Press, 2011.

[9] A. Pascale, T. Urmee and A. Moore, "Life cycle assessment of a community hydroelectric power system in rural Thialand," Renewable Energy, vol. 2011, no. 36, pp. 2799-2808, 2011.

[10] F. Zotlöterer, "Zotlöterer Smart Energy System Home Page," [Online]. Available:

http://www.zotloeterer.com/welcome/gravitation-watervortex-power-plants/. [Accessed 1406 2016].

[11] "Genossenschatt Wasserwribe - Home Page," [Online]. Available: http://gwwk.ch/. [Accessed 2306 2016].
[12] "KourisPower Ltd. Home Page," 2016. [Online]. Available: http://www.kourispower.com/. [Accessed 23 06 2016].

[13] O. B. Yaakob, Y. M. Ahmed, A. H. Elbatran and H. M. Shabara, "A Review on Micro Hydro Gravitational Vortex Power and Turbine Systems," Jurnal Teknologi, vol. 69, pp. 1-7, 2014.

[14] S. Mulligan and P. Hull, "Design and optimisation of a water vortex hydropower," Department of Civil Engineering and Construction, IT Silgo, Sligo, 2010.

[15] S. Wanchat, R. Suntivarakom, S. Wachat, K. Tonmit and P. Kayanyiem, "A parametric study of gravitational water vortex power plant," Advanced Materials Research, Vols. 805-806, pp. 811-7, 2013.

[16] Wanchat and R. Suntivarakom, "Preliminary design of a vortex pool for electrical generation," Department of Mechanical Engineering, Khon Kaen University, Khon Kaen, 4 Feb 2015.

[17] T. R. Bajracharya, S. Dhakal, S. Nakami, P. Pun and A. B. Thapa, "Development and Testing of Runner and Conical Basin for Gravitational Water Vortex Power Plant," Center for Applied Research and Development(CARD), Tribhuvan Univeristy, Kathmandu, 2013.

[18] T. R. Bajracharya and R. K. Chaulagain, "Developing innovative low head water turbine," Center for Applied Research and Development(CARD), Tribhuvan University, Kathmandu, 2012.

[19] S. Dhakal, "Comparison of cylindrical and conical basins with optimum position of runner: Gravitational water vortex power plant," Renewable and Sustainable Energy Reviews, vol. 48, pp. 662-669, 2015.

[20] C. Power, A. McNabola and P. Coughlan, "A Parametric Experimental Investigation of the Operating Conditions of Gravitational Vortex Hydropower (GVHP)," Journal of Clean Energy Technologies, vol. 4, no. 2, pp. 112-119, March 2016.

[21] R. W. Fox, J. Pritchard and T. McDonald, Introduction to fluid mechanics, John Wiley \& Sons, 2008.

[22] M. Nechleba, Hydraulic Turbines: Their Design and Equipment, London: Constable \& Co. Ltd, 1957.

[23] A. Sayma, Computational Fluid Dynamics, Bookboon, 2009.

[24] B. R. Munson and D. F. Young, Fundamentals of Fluid Mechanics, Ames, lowa: John Wiley \& Sons, 2006. 
[25] B. S. Massey and J. Ward-Smith, Mechanics of Fluids, London: CRC Press, 1998.

[26] Ravindra Nair, "Community Development and Energy equality; Experiences from micro hydro implementation in trivial settlement of India. IEEE Region 10

Humanitarian Technology Conference (R10-HTC), 2016.

[27] K. M. \&. M. P. Prakash Kafle, "Modeling of Local Rural Grid Connection of Cluster based Micro Hydro Power Plant," $5^{\text {th }}$ International Conference on Wireless

Networks and Embedded Systems (WECON), 2016.

[28] Aleem Ahemed Khan, "A Simple and Economical Design of MicroHydro Power Generation System”, 2015 Power Generation System and Renewable Energy Technologies (PGSRET), pp 1-7, 2015. 